\title{
How Intercultural Education is Dealt within Western Societies: Interpretations and Considerations
}

\author{
Seyfi Ozguzel ${ }^{1}(\mathbb{D})$, Seyhan Hasirci ${ }^{2}\left(\mathbb{D}\right.$, Mehmet Tuzel $^{3^{*}}$ (])
}

${ }^{1}$ Cukurova University, TURKEY

${ }^{2}$ Nisantasi University, TURKEY

${ }^{3}$ Sedat Simavi Endustri Meslek Lisesi, TURKEY

*Corresponding Author: mehmet.tuzel@yandex.com

Citation: Ozguzel, S., Hasirci, S., \& Tuzel, M. (2021). How Intercultural Education is Dealt within Western Societies: Interpretations and Considerations. Mediterranean Journal of Social \& Behavioral Research, 5(2), 23-27. https://doi.org/10.30935/mjosbr/10915

\begin{abstract}
In this article we focus on intercultural education and ethnic - cultural diversity in the context of international migration and mobility. Hereby this article aims to contribute to theory development and to provide empirical knowledge that will inform and stimulate research, education, societal debate, as well as social interventions in the educational world.The general objective of this article is to understand the differences in expectations, sensitivities, and nuances in multicultural societies, concentrating on the cultural interactions at various levels and the importance of intercultural communication awareness and skills so that intercultural education can be given in a more efficient way. Specifically, this will provide a national and international academic discussion for scientists and professionals about the implementation of Intercultural Education in the schools. Because the main aim is for all of us to ensure equality for all.
\end{abstract}

Keywords: super diversity, intercultural education, transcultural, multi-ethnic, multi-culture, plural

Received: 6 Mar. 2021 Accepted: 20 Apr. 2021

\section{INTRODUCTION}

This article will breakdown the functions of the education systems particularly (a.) General role of education, (b.) The role of schools, and (c.) Relations Schools and society.

After the introduction of the functions of the education systems, the definition of terms of intercultural education are discussed. Following this chapter are the approaches to intercultural education as part of multi-cultural policy worked out: a. The cultural/pluralistic approach, b. The structural/egalitarian approach, c. combination of a and $b$. (A combination of first two approaches), d. The transcultural approach, e. The knowledge-oriented approach, f. Social training.

And in the final paragraph are the most common methods and techniques discussed.

\section{THE FUNCTION OF THE EDUCATION SYSTEM}

General Role of Education

- to give every individual access to education

- to provide all pupils and students with opportunities to develop as Individuals
- to build on the diversity of lifestyles and backgrounds of pupils and students

- ultimately to ensure that all pupils and students can participate in society to the full

- The Advisory Council for the First Stage of Secondary

Education (ARVO-I) has the following objectives:

a. General cognitive objectives

b. Culture-related cognitive objectives

c. General skills

d. Social objectives

\section{The Role of Schools}

The objective of schools in relation to that of the education system as a whole is to equip pupils and students to function effectively as adult members of society. The schools achieve their objective in three ways: by encouraging pupils and students to develop as individuals, by preparing them for work and by preparing them to live as adults in society.

Schools and Society

Schools are a product of society but they are not islands. They are affected by the realities of the society of which they are part. In other words, society and the education system constantly influence one 
another. As - we now live in a multi-cultural/multi-ethnic society, the education system will have to achieve its objectives within the context of that type of society. Based on its stated general objectives, the education system is seeking to create Intercultural Education (ICE), a form of education which reflects the multi-ethnic and multi-cultural situation which exists in the Netherlands today.

\section{Definition of Terms}

- Ethnic groups: Ethnic groups are groups of people characterised by their race, nationality, language, lifestyle or religious beliefs.

- Cultural groups: These are groups characterized by a system or network of values, standards, habits and customs. The system shapes the relationships of the members of the group with one another and with their surroundings.

- Social scientists clarify the term "ethnic minority" by saying that ethnic origin is much broader than cultural background.

\section{Speakers of other language than the national language}

This implies that if the language problems were solved, no problems would remain, so the term is incomplete/incorrect. "The terms used in other countries to describe Intercultural Education (ICE) do not correspond fully with those used in the Netherlands. For example, (Sarup, 2013) speak of "multi-racial education". Lynch, another British author, uses the term "multi-cultural education". (Claydon, 1981) writing from an Australian perspective, use the term "multi-cultural schooling" (Banks, 2013), whose analysis is based on the situation in the United States, prefer "multi-cultural education and multi-ethnic education" (Banks, 1993).

\section{INTERCULTURAL EDUCATION (ICE)}

In Latin, "inter" can mean "between" or "among", "with one another" or "on one another", "mutual" or "reciprocal". It is added to adjectives and nouns to refer to something existing or happening between similar things or groups of people. As part of the term "Intercultural Education" its meaning is not therefore confined to two ethnic groups, it relates to a large number of groups. By definition, "Inter" as used in "Intercultural" is general rather than categorical, indicating mutual dependence, harmony and understanding. "Cultural", "ethnic" and "racial" are interchangeable to a certain extent but they do not always mean the same thing (Zembylas \& Iasonos, 2010).

\section{The Cultural/Pluralistic Approach}

This approach stresses mutual understanding, respect and harmony. It does not see ICE as a way of dealing with ' the educational disadvantages of minority groups but emphasises cultural rather than social identity. Its aim is to bring together people from different ethnic and cultural backgrounds.

"The main emphasis of the cultural/pluralistic approach is on integration. Education is a way of helping ethnic groups to become involved in all aspects of the life of the community without giving up a large part of their own identity, as they see it. Advocates of this approach believe that education should focus on cultural pluralism. They therefore ask how education can best produce and maintain a delicate balance between two conflicting pressures: that exerted on minorities by the dominant groups in society to assimilate and the pressure from some minority circles to remain segregated. Sooner or later the question arises as to how the pluriform nature of society relates to the ideal of greater social cohesion." In other words, "the ideal of the multi-cultural approach is to strike a balance between the preservation of ethnic values on the one hand and an adjustment to the prevailing values of society as a whole on the other. According to this approach, the cultures of majority and minority ethnic groups exert a constant influence on one another. The social and cultural inequality which exists between majority and minority ethnic groups must be reduced by achieving a consensus in the prevailing value system." But in the multicultural approach here are two serious objections: First it devotes insufficient attention to the different positions of majority and minority ethnic groups within the existing power structure and second it focuses on the concept of culture rather than ethnic background (Mertens, 2010).

\section{The Structural/Egalitarian Approach}

This approach takes the inequitable relationship which exists in society between the majority and the minority as its starting point. The aim of ICE must therefore be to provide minority ethnic groups with better educational and job opportunities. The Proponents of the structural/egalitarian approach are mainly concerned with equality and with how the education system can create better educational and employment opportunities for children from ethnic minorities. Seen in terms of this egalitarian model, pluralism is not unimportant but it is subordinate to the problem of the unequal distribution of income, power and status among all groups in society. The idea of an integrated, multi-cultural and pluriform society will remain a nebulous abstraction if it is not rooted in an analysis of the determinants of inequality in the education system and society as a whole. Essentially this means the way prejudice, racism and discrimination adversely affect the opportunities of ethnic groups. The problem of this idea is that different ideals of equality are obviously difficult to reconcile with one another, which is why doubts must also exist about combining egalitarian and pluralistic objectives (Kowalczewski, 1982). Assuming that intercultural education derives from a view of society which respects the position of ethnic groups and values the contribution they can make; doubts must be raised about the relatively one-sided emphasis of the ideological principles of current minorities policy which merely seek to abolish the disadvantages of specific groups.

The multi-ethnic approach uses ethnic origin as a classification principle and at the same time recognizes that adjustment between ethnic groups depends on their relationships within the existing power structure. Proponents of this view believe that multi-ethnic education can play an important role in creating more equal opportunities in education and society for minority ethnic groups. Pupils from minority groups must reinforce their ethnic identity and acquire the skills which will give them greater power, thereby avoiding the dangers of violence and further isolation. Pupils from majority groups must change their ethnocentric or racist attitudes towards minority groups, from a desire to share power. This approach is therefore based on harmonious shifts in the existing power structure (Yassir, 2017).

The anti-racist approach concentrates on the underlying causes of inequality and less on cultural or ethnic identity and the related problems found in a western, industrialised society. Its starting point is the exclusion, suppression, discrimination and racism experienced by all ethnic minorities. The anti-racism approach seeks to alter the existing power structure and believes that this requires far-reaching changes in society. The redistribution of power will inevitably involve an anti-racist struggle, a combined struggle against all forms of 
inequality such as racism, sexism and class distinction. Proponents of the multi-ethnic approach are aware that the harmonious route can only produce change over a long period of time since the majority will not willingly give up its position. Change will therefore require major efforts on the part of both majority and minority groups believes that if intercultural education is based on culture, it can confirm prejudices and stereotyping since it reduces culture to artefacts taken from a limited number of its constituent elements such as religion, music or diet. There is a problem in this: The broad objectives of the anti-racist approach (removing all forms of inequality) deserve support, but the limited effect of education in this area should be recognised (Boonen, 2003). The anti-racist approach heavily overestimates the power of the education system to deal effectively with the causes of racist behaviour and other forms of inequality. And another problem is: If we are to help pupils to live harmoniously with one another by breaking down the barriers between different ethnic origins, cultures, languages and religions we must combat prejudice, discrimination and racism. However, to regard inter-ethnic and intercultural education exclusively as anti-racist education would be to impoverish it and would be unacceptable from a teaching point of view. Anti-racist trend is based on a negative premise: "It is not enough to teach children to be "anti" this or "anti" that. The main emphasis should be on being "pro" this or "pro" that or better still, on creating an awareness of interdependence and mutual influences expressed by the prefix "inter".

\section{A Combination of Both Approaches}

Experts regard ICE as multi-cultural education, the aim of which is to achieve greater cohesion between people from different ethnic and cultural backgrounds. Others see ICE as anti-racist structural/egalitarian education. Many experts want ICE to pay attention to both the multi-ethnic and multi-cultural aspects, with the aim of breaking the mould of mono-cultural education. "In recent years, the views of supporters of the multi-cultural approach and those of advocates of the anti-racist approach have polarised. This shows that intercultural education can effectively combine the multi-cultural approach and the. anti-racist or egalitarian approach in terms of the common objective of ultimately seeking to promote good inter-ethnic relations. The relationships can vary from obvious racism to mutual respect and cooperation. The hierarchy can be expressed in diagram form as follows: Education in these terms should not confine itself to the society in which it is based, it must also have a world dimension: cooperation, respect, tolerance, preferences, prejudice, discrimination and obvious racism. "The equal opportunities approach to intercultural education is mainly concerned with eliminating prejudice, discrimination and racism in order to improve the opportunities of ethnic groups. Cooperation based on mutual respect is impossible in an educational situation where pupils openly discriminate against one another. The education system must therefore combat such behaviour and help pupils develop the skills which will enable them to live in harmony. The concept of intercultural education as bringing together people from different ethnic and cultural backgrounds operates in the higher echelons of the hierarchy. Steps can be. taken to develop constructive relationships in the areas of the education system where tolerance already exists." (Eldering, 2006).

\section{The transcultural approach}

The basic premise of the transcultural approach is that culture is a form - of acquired behaviour which serves to exclude others. Teaching has become subordinate to culture whereas it must remain above it. The education system must employ the appropriate teaching methods to promote the rights of people in society.

- The transcultural approach therefore argues that intercultural education must provide all pupils and students with opportunities to identify with art, literature, music and dance and must give such subjects a natural role within the total curriculum.

- Intercultural education must "problematise" the lifestyles of pupils, to borrow a term from Paulo Freire. It must offer information and learning experiences to provide pupils with a better understanding of 'the historical, socio-economic, cultural and personal factors which influence their lives. This means, for example, that different languages or the fact that some pupils speak more than one language will be essential features of intercultural education. This confronts pupils with the similarities and differences between cultural systems which exist to solve the problems of existence. A confrontation with people who speak more than one language is part of cultural education for monolingual pupils and teachers. Recognition of the fact that other people. Speak more than one language is a way of acknowledging the diversity of ways in which the world we live in can be described and explained (Ağırdağ, 2016).

- Intercultural education must be an integral part of all aspects of the learning and teaching process. The concept of "Dutch, culture" must be dealt with more effectively so as to do justice to the tremendous diversity which already exists.

\section{The knowledge-oriented approach}

This is a rational approach based on promoting a knowledge and understanding of ethnic relationships/critical thinking in order to eliminate indoctrination and prejudice.

"In many respects the fight against prejudice and discrimination precedes the fight against racism. Discrimination and prejudice will be more likely to exist and flourish in the absence of a knowledge and understanding of ethnic relationships. These objectives lie in the area between the cognitive and affective domains of learning, which are closely related to one another."

"Creating a greater knowledge and understanding of ethnic relationships is not primarily a matter of becoming better informed about other people's cultures and customs. It means having a greater awareness and more ability to perceive the importance of ethnic factors in the way people deal with one another. it would be undesirable to place a one-sided emphasis on dealing with prejudice. Numerous factors outside the scope of the education system influence ethnic prejudices. International research shows that education has a relatively good chance of producing positive results if it succeeds in promoting "knowledge and understanding" and "critical thinking and observation among pupils" (Eldering, 2006).

"Increasing knowledge and understanding" and "learning to think and observe critically" are essential. Allport favours a long-term educational programme based on promoting "knowledge and understanding". This would deal with topics such as the meaning of relevant concepts, the characteristics of ethnic groups, the differences and similarities between groups, different ways of learning to think, the working of the scapegoat mechanism, the consequences of discrimination, facts about discrimination and learning that several loyalties are possible. Learning to think and observe critically ties in 
with the previous approach in many ways. Its main objective is to change "the cognitive structure underlying prejudice. Intercultural education is a process whereby cultures and cultural carriers influence one another and interact. We would define intercultural education as education based on objectives, a curriculum and a form which fully reflect the fact that we live in a multi-cultural society. The ultimate goal of intercultural education is to provide children with an opportunity to acquire different attitudes, to adopt a different position in relation to, their surroundings in the widest sense of the word. However, it is vitally important that new attitudes should also give rise to a willingness to behave in a different way (Boukema et al., 1994). A change in attitude is not synonymous with a change in behaviour, which is of course the ultimate goal. It will be achieved through conviction based on new arguments, correct and full assessments tut equally on good and relevant information. Prejudice and discrimination will not change of their own accord. They must be tackled systematically by means of information campaigns and education. Intercultural education should therefore seek to achieve the following: a) to transfer knowledge about the cultures and cultural expressions of different ethnic groups, not excluding any single group; b) to combat prejudice which fosters discrimination; and c) to fight racist behaviour (Claydon, 1981).

\section{Social training}

This approach sees ICO as a dimension of existing education, which devotes attention to attitudes and behaviour which recognise the equality of human beings. It is based on a combination of understanding, contact, and respect designed to create equality.

"According to this approach, intercultural education focuses on existing and future relationships between people from different ethnic backgrounds. Its starting point is the multi-ethnic nature of the society in which all children are growing up. The importance of mutual respect, harmonious relationships and interaction between people from different ethnic backgrounds should become an integral part of the entire education system."

"Furthermore, intercultural education based on this fairly broad objective focuses on providing pupils with training in social skills which will help them to function as adults in a multi-racial society. This approach regards intercultural education as a dimension of existing education, which is concerned with developing attitudes and behaviour which recognise the equality of all people irrespective of their ethnic background. For this development to take place, pupils must understand ethnic relationships. They must come into contact with pupils from other ethnic groups if possible, they must learn to put themselves in other people's shoes and to respect other people as being different. Intercultural education as social training therefore embraces both the aim of increasing knowledge and understanding (the rational approach) and the aim of bringing different cultures and ethnic groups together. These are steps en route to the more distant goal of everyone living and working harmoniously as equals in a multi-ethnic society (Drijkoningen \& Frijns, 2011).

This approach to intercultural education is also concerned with combating racism and the discriminatory practices to which it gives rise. Racism is the most far-reaching violation of the. principle of equality. We do not exclude the possibility that relationships in society will be positively affected in the long term if children learn anti-racist behaviour, but we do not cherish the illusion that anti-racist education will bring about direct changes in society.
Objectives of intercultural education: The "Gamma" source book defines the objective of intercultural education for pupils as follows: the aim of intercultural education is to create attitudes and behaviour in children which recognise and respect the equality of people from any type of ethnic background,' so that they promote mutual understanding and interaction between people of different ethnic origins and stimulate an awareness of the positive value of ethnic diversity.

\section{THE MOST COMMON METHODS AND TECHNIQUES}

\section{The Cultural/Pluralistic Approach}

- group discussions

- talks by individual children on relevant subjects

- schools decorated in a way which. reflects ethnic diversity

- teaching staff drawn from different ethnic groups

- theme evenings/afternoons

- ICO as an activity pursued by the entire teaching staff of a school

Structural/Egalitarian Approach (Anti-Racist)

- confrontation with racism in the classroom and in society

- projects aimed at combating prejudice/discrimination

- professional development/training of teachers

- screening teaching materials in terms of ICO

- ICO as an activity for the entire teaching staff

- attempting to ensure that pupil populations in schools reflect the composition of society

Transcultural Approach

- talks by individual children

- themes such as historical, social and economic developments in society as part of the appropriate subjects

- making the individual central to all approaches

- ICO as an activity for the entire teaching staff

- stressing the value of a diversity of cultures so children will see their own culture in perspective

\section{Knowledge-Oriented Approach}

- intercultural projects/days/festivities

- modifying the curriculum in subjects such as social studies, history, "religious movements" and geography

- providing information by or about ethnic groups

- visits to cultural establishments

- school trips

- ICO as an activity pursued by the entire teaching staff

\section{Social Training}

- group discussions in class

- more emphasis on equality in subjects such as environmental studies and life skills

- encouraging individual children to visit one another's homes

- teaching children, the positive value of cultural diversity 
- ICO as an activity pursued by the entire teaching staff (Luijten, 2006).

\section{CONCLUSION}

As a result of mobility and migration in the world, there are many societies with different ethnic, lingual and cultural diversities. In some mega cities the society has a super diversity; where people with more than 100 ethnic-, cultural and lingual differences live together.

ICE is not a separate course subject to be taught in schools rather it is the philosophy as explained before in the subject matter, that must be integrated in all parts of education which includes the contents of all the subjects as well as educational environments in places where education is provided.

Educational systems should be able to reflect all aspects of the society; teachers, managers and helping staff of education institutions should be appointed based on society's cultural complexity and should be by merit. The pupils/students have to recognize the similarities between their personality as individuals, members of specific cultural/ethnicities and the education system.,

Author contributions: All authors were involved in concept, design, collection of data, interpretation, writing, and critically revising the article. All authors approve final version of the article.

Funding: The authors received no financial support for the research and/or authorship of this article.

Declaration of interest: Authors declare no competing interest.

Data availability: Data generated or analysed during this study are available from the authors on request.

\section{REFERENCES}

Ağırdağ, O. (2016). Respect voor etnisch-culturele identiteiten zorgt voor méér onderwijsprestaties, niet minder [Respect for ethnic-cultural identities ensures more educational performance, not less] DeMorgen. Available at: https://www.demorgen.be/nieuws/ respect-voor-etnisch-culturele-identiteiten-zorgt-voor-meeronderwijsprestaties-niet-minder b050bde6/? referer=https\%3A\% 2F\%2Fwww.google.com\%2F

Banks, J. A. (1993). Multicultural Education: Historical Development, Dimensions, and Practical. Review of Research in Education, 19, 3-49. https://doi.org/10.3102/0091732X019001003
Banks, J. A. (2013). Citizenship education and migration. The Encyclopedia of Global Human Migration. https://doi.org/10.1002/ 9781444351071.wbeghm137

Boonen, R. (2003). Bouwstenen voor intercultureel onderwijs [Building blocks for intercultural education]. Apeldoorn Garant.

Boukema, H. J., Ringnalda-Lels, J., Weersma, A. A., \& Westerman. W. E. (1994). Gamma bronnenboek voor intercultureel onderwijs [Gamma source book for intercultural education]. Association of Educational Advisory Centres. Available at: https://www.dbnl.org /tekst/_tsj001199401_01/_tsj001199401_01_0047.php

Claydon, L. F. (1981). Common or Core Curriculum and Culture. Discourse: Studies in the Cultural Politics of Education, 2(1), Published online: 06 Jul 2006. https://doi.org/10.1080/0159630810020101

Drijkoningen, J., \& C. Frijns (2011). Allemaal in (inter)Actie! - Een praktijkgericht didactisch model over omgaan met heterogeniteit in Ouders in (inter)Actie!- en KAAP-groepen. In Opdracht van het Impulsfonds voor het Migrantenbeleid. Centrum voor Taal en Onderwijs.

Eldering, L. (2006) Cultuur en opvoeding. Lemniscaat.

Kowalczewski, P. S. (1982). Race and Education: Racism, Diversity and Inequality, Implications for Multicultural Education. Oxford Review of Education, 8(2), 145-161. https://doi.org/10.1080/ 0305498820080204

Luijten, I. (2006). Intercultureel onderwijs de creatieve kracht van de media [Intercultural education is the creative power of the media]. In tijdschrift voor kunst en cultuur in het onderwijs (pp 8-10). Kunstzone. https://www.lkca.nl/informatiebank/intercultureelonderwijs-de-creatieve-kracht-van-de-media

Mertens, E. (2010). 'Omgaan met diversiteit' binnen het onderwijs ["Dealing with diversity" within education]. Universitetit Gent - Faculty of Psychology Pedogogy. https://lib.ugent.be/fulltxt/RUG01/001/ 460/244/RUG01-001460244_2011_0001_AC.pdf

Sarup, M. (2013). The politics of multiracial education. Routledge. https://doi.org/10.4324/9780203061091

Yassir, F. (2017). Superdiversiteit in het onderwijs? Europa toont dat het kan [Super diversity in education? Europe shows that it is possible]. Available at: https://www.knack.be/nieuws/belgie/superdiversite it-in-het-onderwijs-europa-toont-dat-het-kan/article-opinion837961.html?cookie_check=1579261564

Zembylas, M., \& Iasonos, S. (2010). Leadership styles and multicultural education approaches: an exploration of their relationship. International Journal of Leadership in Education, 13(2), 163-183. https://doi.org/10.1080/13603120903386969 